\title{
Influence of Soda Pulping Variables on Properties of Pineapple (Ananas comosus Merr.) Leaf Pulp and Paper Studied by Face-Centered Composite Experimental Design
}

\author{
Jantharat Wutisatwongkul, ${ }^{1}$ Nandh Thavarungkul, ${ }^{1}$ \\ Jirawan Tiansuwan, ${ }^{2}$ and Preecha Termsuksawad ${ }^{1}$ \\ ${ }^{1}$ Integrated Product Design and Manufacturing Program, Division of Materials Technology, School of Energy, \\ Environment and Materials, King Mongkut's University of Technology Thonburi, 126 Pracha Uthit Road, Bang Mod, \\ Thung Khru, Bangkok 10140, Thailand \\ ${ }^{2}$ Division of Thermal Technology, School of Energy, Environment and Materials, King Mongkut's University of Technology Thonburi, \\ 126 Pracha Uthit Road, Bang Mod, Thung Khru, Bangkok 10140, Thailand
}

Correspondence should be addressed to Jantharat Wutisatwongkul; jantharat85@gmail.com

Received 23 November 2015; Accepted 14 March 2016

Academic Editor: Belal F. Yousif

Copyright ( 2016 Jantharat Wutisatwongkul et al. This is an open access article distributed under the Creative Commons Attribution License, which permits unrestricted use, distribution, and reproduction in any medium, provided the original work is properly cited.

Face-centered composite design (FCC) was used to study the effect of pulping variables: soda concentration (4-5 wt $\%)$, temperature $\left(90-130^{\circ} \mathrm{C}\right)$, and pulping time (20-60 $\left.\mathrm{min}\right)$ on the properties of pineapple leaf pulp and paper employing soda pulping. Studied pulp responses were screened yield and lignin content (kappa number). Paper properties, which include tensile index, burst index, and tear index, were also investigated. Effects of the pulping variables on the properties were statistically analyzed using Minitab 16. The optimum conditions to obtain the maximum tensile index were soda concentration of $4 \mathrm{wt} \%$, pulping temperature of $105^{\circ} \mathrm{C}$, and pulping time of $20 \mathrm{~min}$. The predicted optimum conditions provided tensile index, burst index, tear index, screened yield, and kappa number of $44.13 \mathrm{kN} \cdot \mathrm{m} / \mathrm{kg}, 1.76 \mathrm{kPa} \cdot \mathrm{m}^{2}, 1.68 \mathrm{~N} \cdot \mathrm{m}^{2} / \mathrm{kg}, 21.29 \mathrm{wt} \%$, and 28.12 , respectively, and were experimentally confirmed.

\section{Introduction}

Nowadays, awareness of environmental issues has increased. One of the concerned issues in Thailand is deforestation for pulp and paper production. New materials have been investigated and applied to replace pulp and paper from wood. Interesting choices are nonwood plants. Nonwood plants residues, which include rice straw [1], bagasse [2], oil palm frond [3], banana stem [4], pineapple crown leaves [5], and sunflower stalks [6], were studied by many researchers.

According to the Food Agriculture Organization (FAO) online databases [7], Thailand was the world leading pineapple producer in 1993-2013. Usually, only pineapple fruit is consumed and the rest are used as household animal feed or left as pineapple plantation compost. The research by Daud et al. [8] indicated that pineapple leaves have chemical composition suitable for paper production. Large amount of pineapple leaves left from harvesting times throughout the year are then a promising alternative source for paper production. The benefits from using pineapple leaf are not only waste reduction and forest conservation but also value added measures for pineapple leaf itself.

Presently, there are many pulping methods, that is, sulfate (kraft), sulfite, soda, and organosolv processes. Sulfate and sulfite are the most popular methods producing up to twothirds of the world production of pulp [9]. However, the use of sulfated chemical agent causes serious environment impact, which is due to the release of sulfur compounds. Organosolv processes use organic solvents as delignifying agents. The processes do not deliver sulfur compounds. Unfortunately, the processes were effective only in pilot plant scale [10]. For this reason, soda pulping process, a traditional pulping method and free of sulfur compounds, was chosen in this research. 


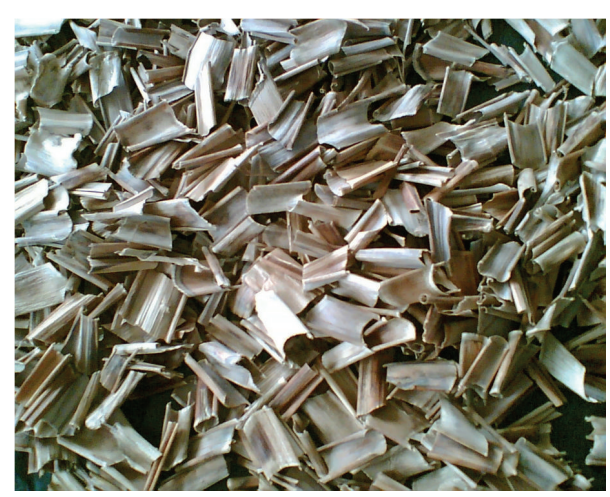

FIgURE 1: Pineapple leaves for pulping.

Soda concentration, liquor to material ratio, temperature, and pulping time are factors in pulping process that affect pulp and paper properties. The liquor to material ratio of $10: 1$ was found to be suitable for pulping of pineapple leave according to previous research [11]. The ratio was used in this work and effects of soda concentration, pulping temperature, and pulping time on pulp and paper properties were investigated. Experimental design for three factors can be conducted by different methods such as one factor at a time (OFAT), full factorial design, and central composite design (CCD). OFAT cannot be used to estimate interaction effects whereas full factorial design requires a lot of experiment runs. In addition, both OFAT and full factorial design cannot be used to obtain the optimal conditions. On the other hand, CCD, one of response surface methods, can be used not only to estimate interaction effect but also to determine the optimal conditions. The specific CCD type, face-centered composite design (FCC) in which alpha $(\alpha)$ is equal to unity, was used in this study to avoid extreme conditions which cannot be applied for pulping [12-14]. Effects of process variables (soda concentration, temperature, and pulping time) on pulp properties (screened yield and lignin content (kappa number)) and paper properties (tensile index, burst index, and tear index) were thus studied employing FCC experimental design.

\section{Materials and Methods}

2.1. Raw Material. Pineapple leaves (Ananas comosus Merr.) were obtained from 1.5-2-year-old pineapple crops in Prachuap Khiri Khan Province, Thailand. Prior to pulping, the leaves were cleaned, cut to approximately $3-4 \mathrm{~cm}$ in length, and sun-dried (Figure 1).

Chemical composition of pineapple leaves was determined in accordance with TAPPI standard methods: T204 om-88 (alcohol-benzene solubility), T207 om-93 (hot water solubility), T212 om-93 (1\% NaOH solubility), T211 om-93 (Ash), T222 om-88 (Lignin), and T223 ts-63 (Pentosan). Holocellulose was quantified using the acid chlorite method of Browning.

2.2. Experimental Design. A specific type of response surface method [13], FCC, was used to investigate effects of
TABLE 1: Levels of each independent pulping variable.

\begin{tabular}{lcccc}
\hline Independent variable & Symbol & \multicolumn{3}{c}{ Levels } \\
\hline Soda concentration $(\mathrm{wt} \%)$ & $S$ & 4 & 4.5 & 5 \\
Temperature $\left({ }^{\circ} \mathrm{C}\right)$ & $T$ & 90 & 110 & 130 \\
Pulping time $(\mathrm{min})$ & $t$ & 20 & 40 & 60 \\
\hline
\end{tabular}

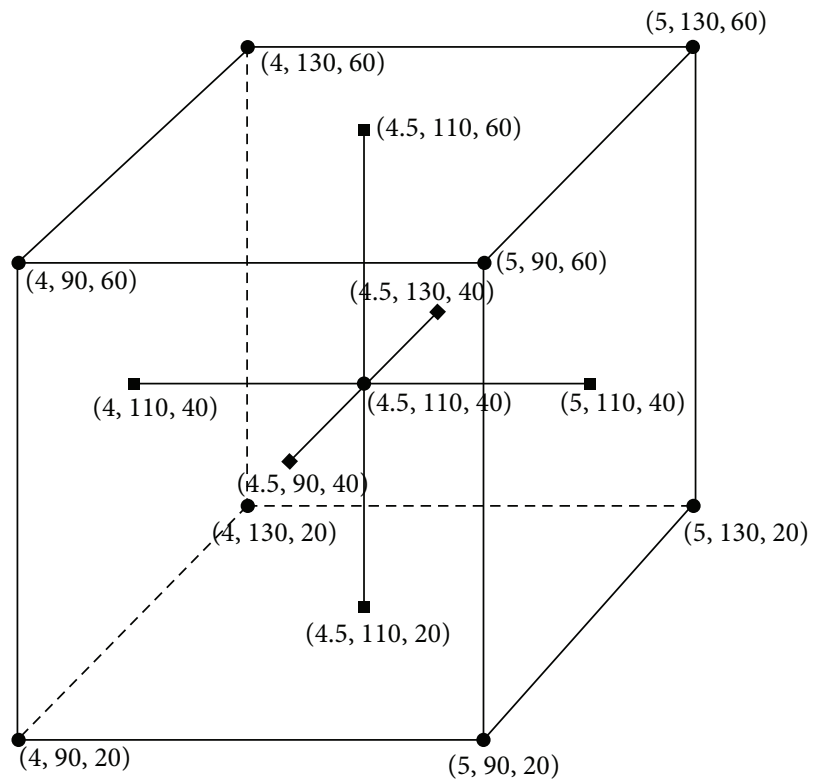

FIgURE 2: Face-centered composite design with three independent variables: the order of number in parentheses is soda concentration (wt\%), temperature $\left({ }^{\circ} \mathrm{C}\right)$, and pulping time ( $\left.\mathrm{min}\right)$, respectively.

soda pulping variables on properties of pineapple leaf pulp and paper. Three pulping variables investigated were soda concentration $(S)$, temperature $(T)$, and pulping time $(t)$. The experimental design matrix is shown in Table 1 . Soda concentration of $2 \mathrm{wt} \%$ was reported to give low tensile index, burst index, and tear index [15], while soda concentration of $6 \mathrm{wt} \%$ provided much lower screened yield than that of $4 \mathrm{wt} \%$. Therefore, selected level of soda concentration in the range of 4-5 wt\% was used in this work. Levels of temperature and pulping time were also selected based on the conditions that entailed satisfying values of tensile index, tear index, and burst index, reported by Khampan et al. [15].

The tested model, shown in Figure 2, shows a series of experiments around a central point (central experiment) to estimate the first- and second-order interaction terms. In this study, fifteen experimental points with two replicates each were selected.

Experimental data were fitted to the second-order polynomial equation (1), where $Z$ represents the response or dependent variables: screened yield, kappa number, tensile index, burst index, and tear index. The letter " $a$ " is a constant and the letters $b$ to $j$ are coefficients of each term:

$$
\begin{aligned}
Z= & a+b S+c T+d t+e S^{2}+f T^{2}+g t^{2}+h S T+i S t \\
& +j T t .
\end{aligned}
$$


TABLE 2: Solubility limit and chemical compositions of pineapple leaves (expressed as percent on a dry weight basis).

\begin{tabular}{lccc}
\hline \multirow{2}{*}{ Solubility and component } & \multicolumn{3}{c}{ Result (\%) } \\
& This work & {$[11]$} & {$[8]$} \\
\hline Solubility & & & \\
(i) Alcohol-benzene solubility & 10.8 & 10.5 & - \\
(ii) Hot water solubility & 18.8 & 25.2 & 32.5 \\
(iii) 1\% NaOH solubility & 64.3 & 65.9 & 39.7 \\
Component & & & \\
(i) Ash & 7.1 & 8.6 & 4.5 \\
(ii) Lignin & 15.0 & 12.9 & 4.2 \\
(iii) Holocellulose & 46.5 & 46.9 & 85.7 \\
(iv) Pentosan & 26.4 & 22.3 & - \\
\hline
\end{tabular}

Note: [11] = Treesuwan (2005) and [8] = Daud et al. (2014).

All statistical analyses were carried out using the statistical software, Minitab 16. Statistica 5.0 software (StatSoft, USA) was used for graphical presentation.

2.3. Pulping. Soda pulping was conducted in a 5-litre rotary digester. The pulping was carried out with liquor to leaf ratio (mL:g) of $10: 1$. Levels of soda concentration, temperature, and pulping time are shown in Table 1. Preheating time of 1020 min was not included in the pulping time.

After pulping, pulp was rinsed with water to remove all chemicals. Then it was mechanically disintegrated by a threeblade mixer and was screened via the flat-plate screen with $0.15 \mathrm{~mm}$ slits. The screened yield was determined after being oven-dried.

2.4. Characterization of Pulp and Paper Sheets. The pulp was analyzed for lignin content (kappa number), in accordance with TAPPI T236 om-99. Screened yield was determined based on weight after drying at $105 \pm 2^{\circ} \mathrm{C}$ for $24 \mathrm{~h}$.

Hand sheets (papers) of $60 \mathrm{~g} / \mathrm{m}^{2}$ were formed. Tensile strength, burst strength, and tear strength of the sheets were obtained according to TAPPI standard test methods (T494 om-96, T403 om-97, and T414 om-98, resp.). The sheets were kept at $23^{\circ} \mathrm{C}$ and $50 \% \mathrm{RH}$ for at least $24 \mathrm{~h}$ before testing.

Fibers and their arrangements were studied using the scanning electron microscope (SEM), NOVA NanoSEM 450, at $10 \mathrm{kV}$. Samples were gold coated prior to entering the vacuum chamber.

\section{Results and Discussion}

3.1. Chemical Composition of Pineapple Leaves. Table 2 shows that pineapple leaves were soluble in the used solvents in the following decreasing order: $1 \%$ sodium hydroxide $>$ hot water $>$ alcohol-benzene. The result indicated that solubility of pineapple leaves was better in alkali. Therefore, the soda process was chosen for pulping method in this study. The table also shows that the main components of pineapple leaves were holocellulose $(46.5 \mathrm{wt} \%)$, pentosan $(26.4 \mathrm{wt} \%)$, lignin $(15.0 \mathrm{wt} \%)$, and ash (7.1 wt\%). The chemical composition of pineapple leaves was close to that found by Treesuwan
[11]: holocellulose (46.9 wt\%), pentosan (22.3 wt\%), lignin (12.9 wt\%), and ash (8.6 wt\%). However, the chemical composition of pineapple leaves in this study was different from that indicated by Daud et al. [8]: holocellulose (85.7 wt\%), lignin (4.2 wt $\%)$, and ash (4.5 wt\%). It should be noted that pineapple leaves used in this study and those of Treesuwan [11] came from the same location, Prachuap Khiri Khan Province, Thailand, whereas those of Daud et al. [8] were grown in Malaysia. Pineapple plants in this study and Treesuwan work experienced similar environment, planting method, and cultivation. The similarity of these parameters may result in similar composition. As shown above holocellulose content of pineapple leaf in this study was only $46.9 \mathrm{wt} \%$; thus, the screened yield obtained from this study was expected to be low.

3.2. Response Surface Analysis of Soda Pulping. Table 3 showed the screened yield, kappa number, and paper properties, tensile index, burst index, and tear index, for various pulping conditions.

The model to predict each response variable of the sample produced by soda pulping process was obtained using Minitab 16. Final models for all variables were shown below as (2)-(6). The equations are reduced models, which showed only significant terms and with significant level or $p$ value of less than 0.05:

$$
\begin{aligned}
\text { Screened Yield }= & -113.1960+13.8739 S+1.8840 T \\
& -0.0058 T^{2}-0.1306 S T \\
\text { Kappa number }= & 66.8272-1.8350 S-0.4499 T \\
& -0.0312 t+0.0015 T^{2} \\
\text { Tensile index }= & 77.5763+1.3723 S-0.3787 T \\
& -0.0438 t+0.0017 T^{2} \\
& -0.0409 S T \\
\text { Burst index }= & 1.0837+0.1954 S+0.0145 T \\
& +0.0107 t-0.0038 S T \\
& -0.0001 T t \\
\text { Tear index }= & 4.6060-0.1280 S-0.0416 T \\
& +0.0066 t+0.0002 T^{2} \\
& -0.00008 T t
\end{aligned}
$$

Table 4 summarized some of the statistical analysis of (2)(6) and the models were verified for the adequacy of final equation by investigating values of $R^{2}$, adjusted $R^{2}$, lack-of-fit, and $p$ value of regression. Table 4 showed that all prediction models possess very high $R^{2}$ and adjusted $R^{2}$ except the screened yield model, whose $R^{2}$ and adjusted $R^{2}$ were only about 70 and 65 percent, respectively. The $R^{2}$ indicates how well the model can explain variation of data and the adjusted $R^{2}$ indicates how much $R^{2}$ overestimates the variance when 


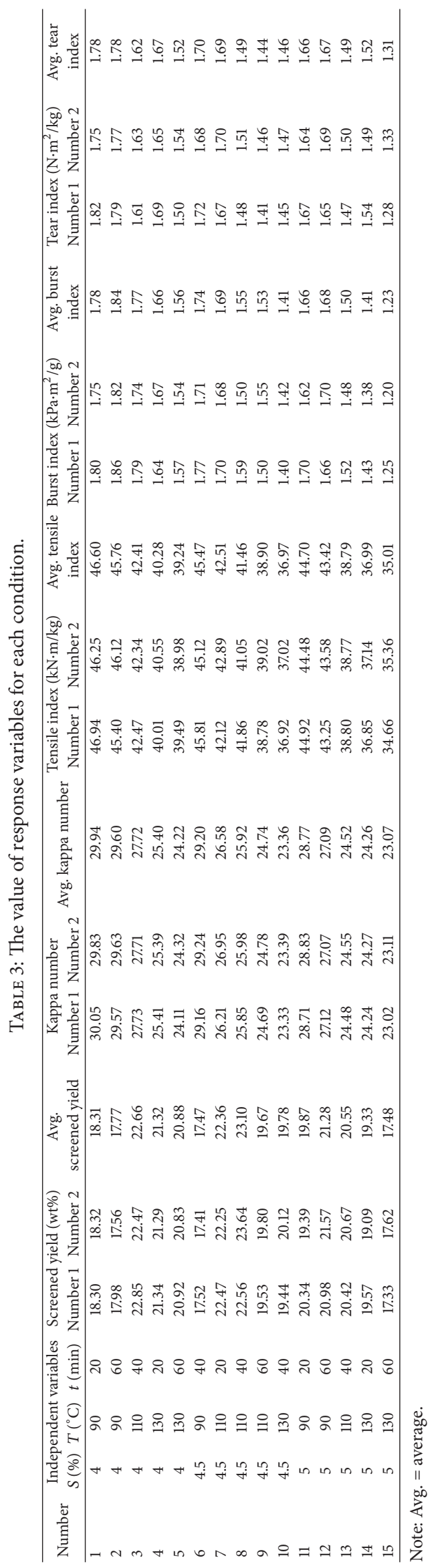




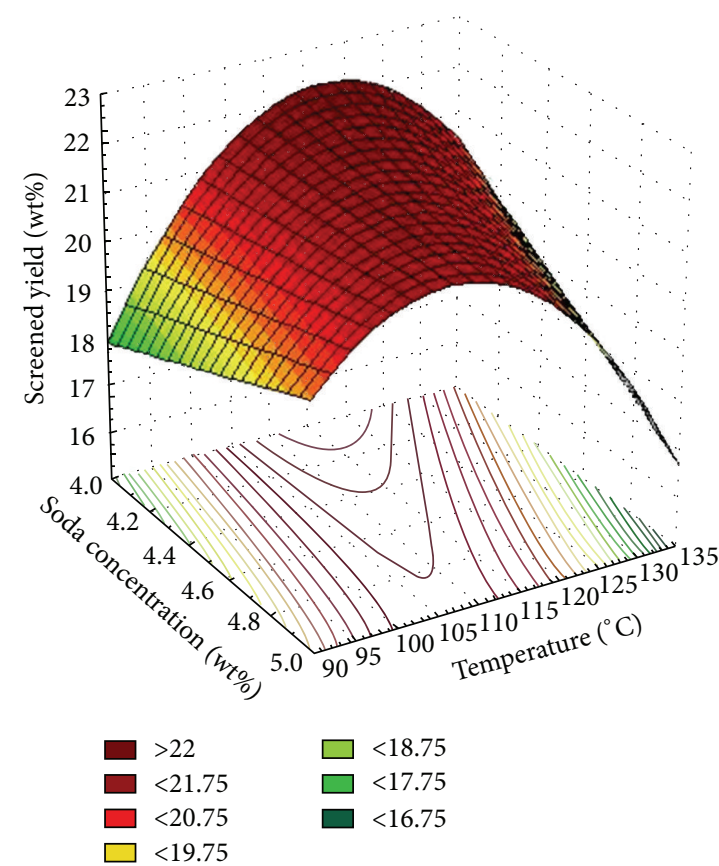

(a)

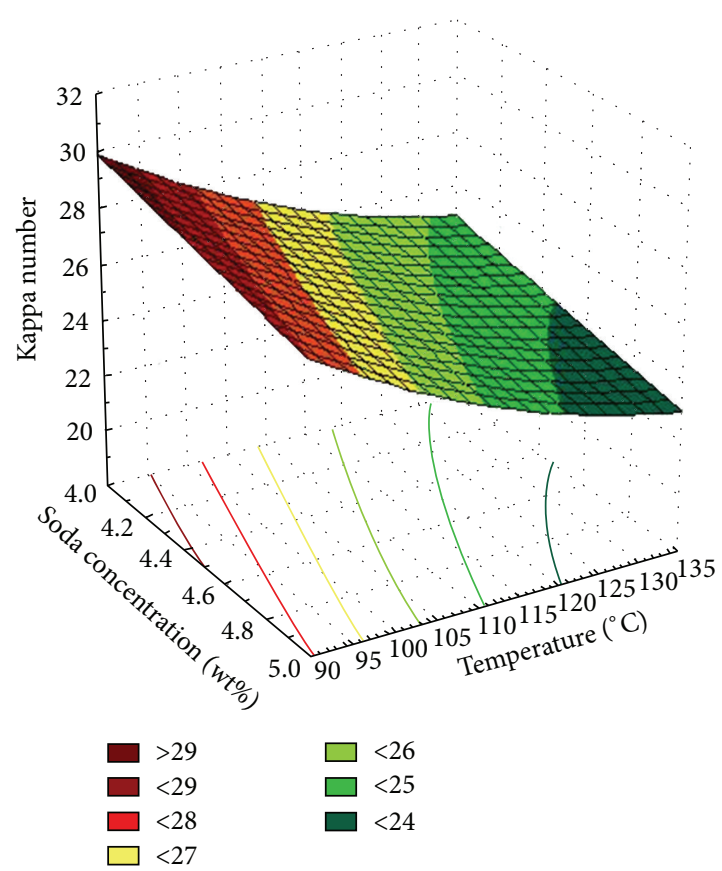

(b)

Figure 3: (a), (b) Surface plot showing the effect of soda concentration and temperature on screened yield and kappa number at 40 min of the pineapple leaf pulp, respectively.

another predictor is added in the model. The higher the adjusted $R^{2}$, the better the goodness of fit.

From Table 4, most models showed excellent goodness of fit except the screened yield prediction model. However, considering lack-of-fit, only the yield model showed insignificant lack-of-fit with significant level of less than 0.05 . The insignificant lack-of-fit indicates that the model is adequate to be used. For the other models, the error analysis was conducted. It indicated that these models were precise as shown in Table 5. Therefore, the other models were well fitted and were suitable to be used to predict the individual responses based on the working conditions.

\subsection{Pulp Properties (Screened Yield and Kappa Number).} From (2) and (3) and the corresponding data in Table 4, soda concentration and pulping temperature possessed significant effects on both screened yield and kappa number. The effects of soda concentration and temperature on screened yield were shown in Figure 3(a). At temperature of $90^{\circ} \mathrm{C}$, an increase of soda concentration slightly increased the screened yield. However, at $130^{\circ} \mathrm{C}$, an opposite effect was found. An increase of soda concentration decreased screened yield. The reasons for these were that soda in pulping was used to remove lignin via hydrolysis reaction, which shortens the polymer chains. Moreover Wanrosli et al. [16] described that lignin chain is destroyed before cellulose chain is destructed. Therefore, it can be deduced that, at $90^{\circ} \mathrm{C}$, lignin chain was broken and dissolved in cooking liquor and cellulose was left behind. As a result, screened yield was high because an increase of soda concentration increased the rate of lignin chain disintegration, while, at $130^{\circ} \mathrm{C}$, hydrolysis was accelerated by an increase of temperature and caused rapid destruction on lignin and further destruction on cellulose chains as well.

From Figure 3(a), at any particular soda concentration, screened yield was increased as temperature increased until reaching the peak in the temperature range of $105-115^{\circ} \mathrm{C}$ and then it was decreased at higher temperature. Acceleration of hydrolysis rate with an increase of temperature was responsible for the destruction of both lignin and cellulose.

For kappa number, with significant level or $p$ value of less than 0.05 , all factors had significant effects on kappa number as shown in Table 4 and Figure 3(b). From the response surface depicted in Figure 3(b), the increases of both soda concentration and temperature decreased kappa number. As discussed previously, both soda concentration and temperature increased hydrolysis rate and thus destroyed lignin chains in the pulp $[16,17]$.

In the soda pulping process, the optimal conditions predicted by Minitab 16 to obtain the highest screened yield of $22.07 \%$ were $4 \mathrm{wt} \%$ soda concentration, $110^{\circ} \mathrm{C}$, and $20 \mathrm{~min}$ pulping time. However, paper produced by the pulping process obtained from the conditions might not possess the highest tensile strength.

3.4. Paper Properties (Tensile Index, Burst Index, and Tear Index). The effects of soda concentration, temperature, and pulping time on paper properties that are tensile index, burst index, and tear index were shown in (4), (5), and (6) and in Table 4. Table 4 showed that only soda concentration and temperature had significant effects on these properties. Figures 4(a), 4(b), and 4(c) demonstrated that high tensile, 


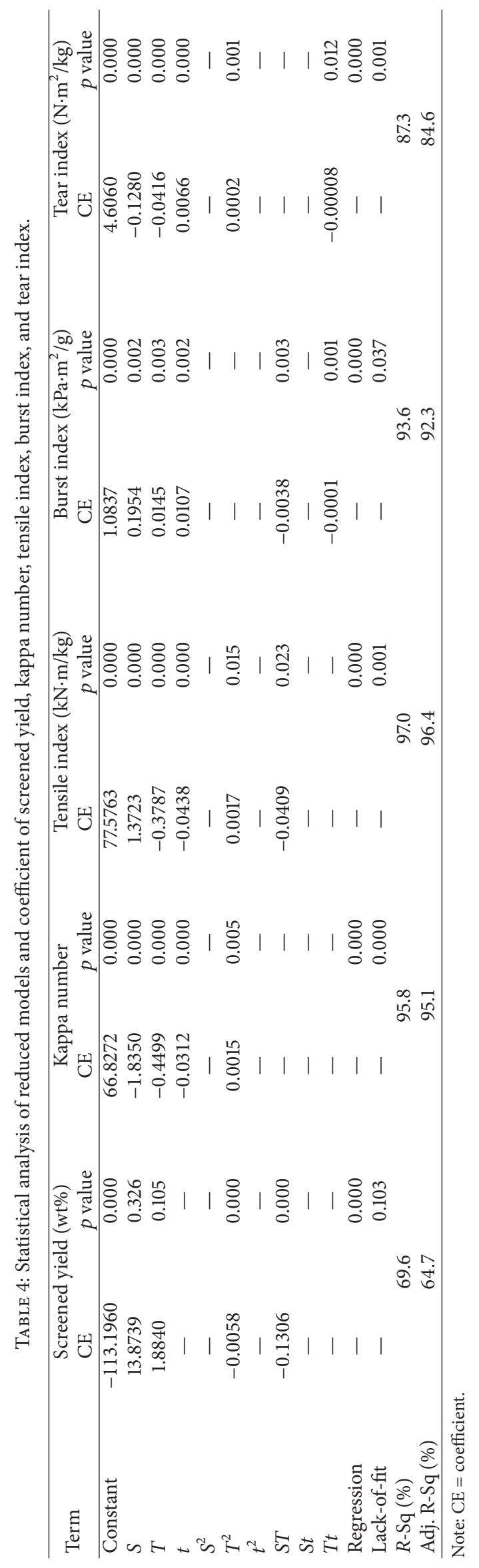




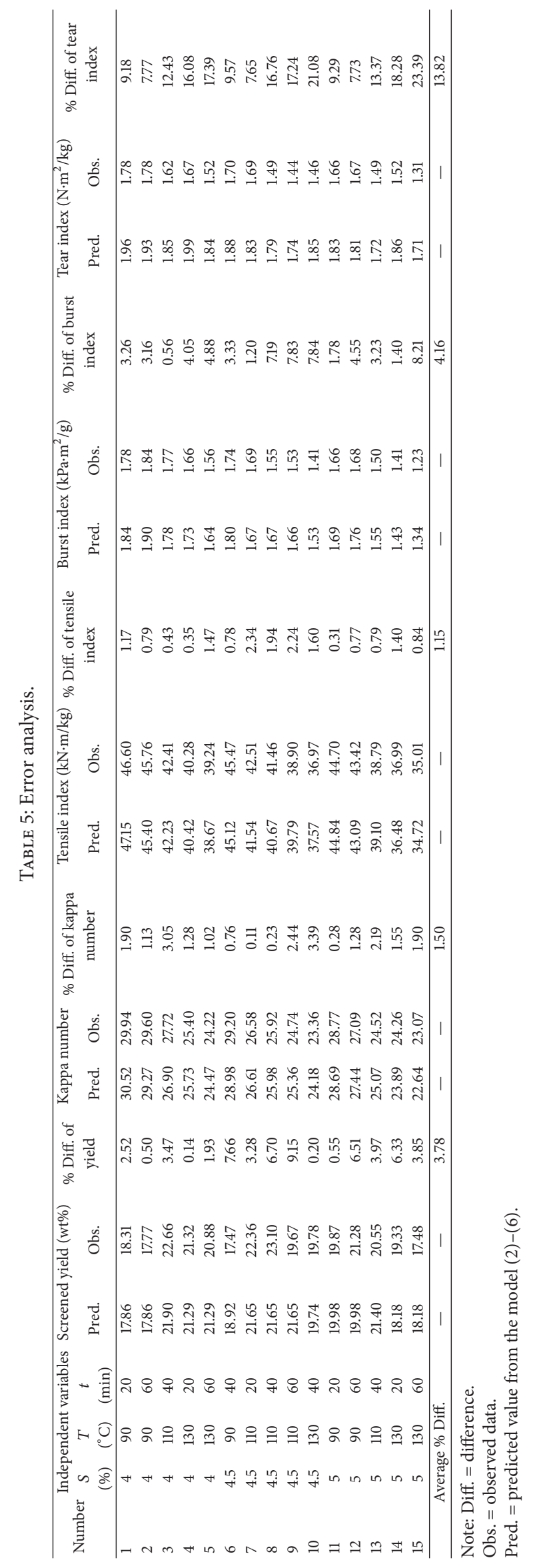




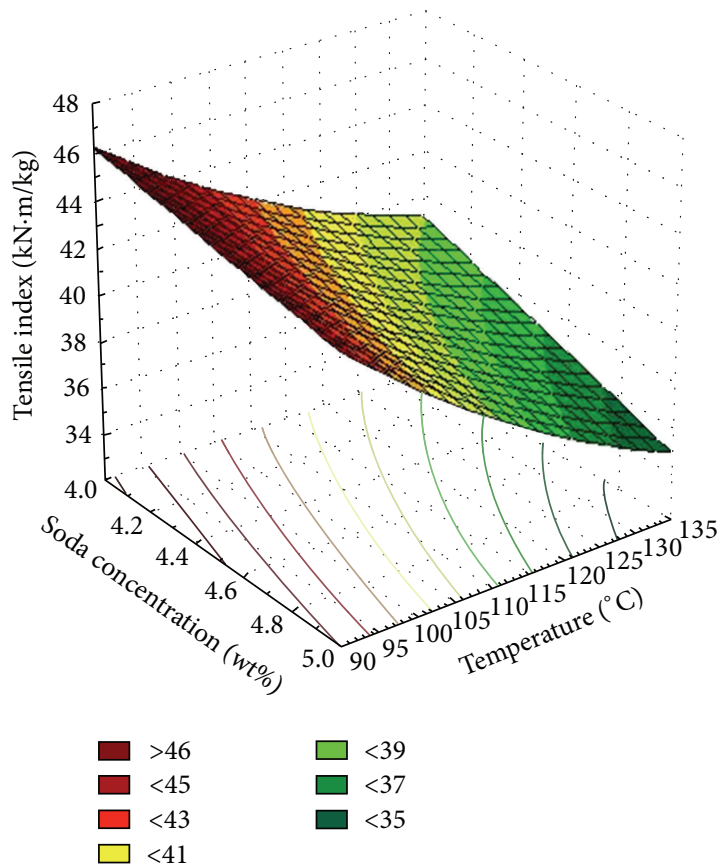

(a)

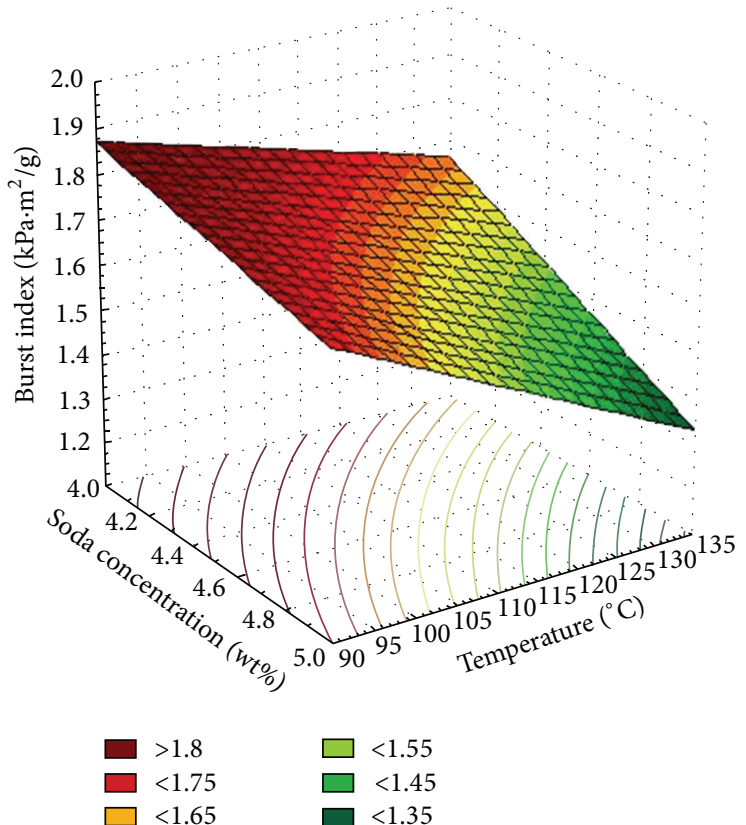

(b)

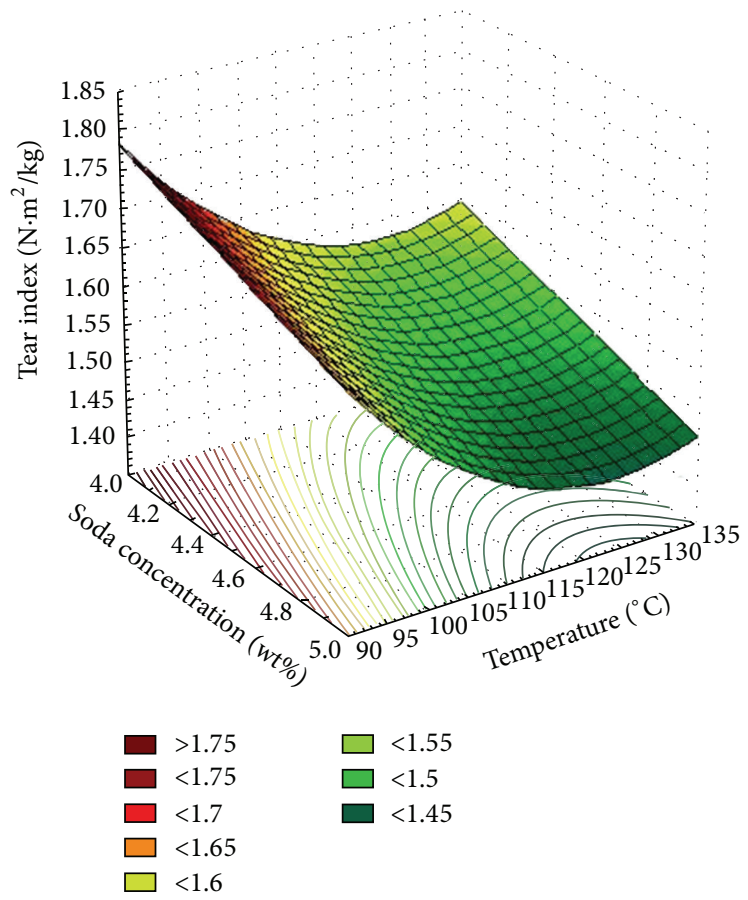

(c)

Figure 4: (a), (b), (c) Surface plot showing the effect of soda concentration and temperature on tensile index, burst index, and tear index at $40 \mathrm{~min}$ of the pineapple leaf paper, respectively.

burst, and tear indices were obtained at the conditions of low soda concentration and low temperature. Hydrolysis rate decreased as soda concentration and temperature decreased, as mentioned before, resulting in less lignin destroyed which in turn imparted paper with high mechanical properties.

The lignin chain destruction was confirmed by SEM images of pineapple leaf paper as shown in Figure 5. The surface morphology of pineapple leaf paper prepared at soda concentration $4 \mathrm{wt} \%$ and temperature at $90^{\circ} \mathrm{C}$ (kappa number $=29.94)$ in Figures 5(a) and 5(b) displayed the fiber linkage by some connective material (areas X and Y), which may be lignin or extractives. In contrast, fewer amounts of connective material existed in pineapple leaf paper prepared at soda concentration $5 \mathrm{wt} \%$ and temperature at $130^{\circ} \mathrm{C}$ (kappa number 


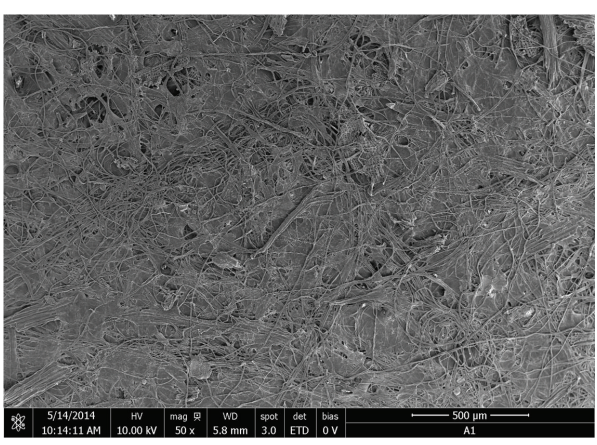

(a)

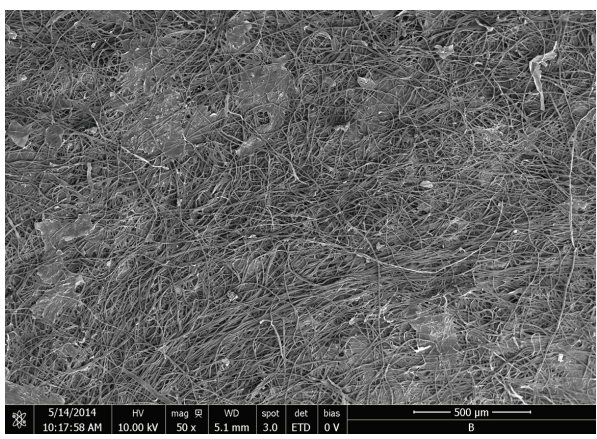

(c)

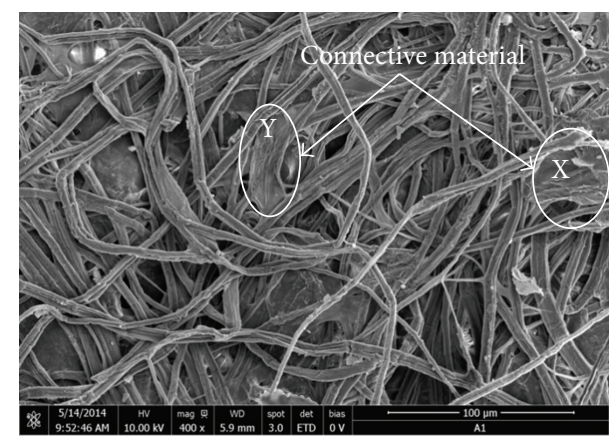

(b)

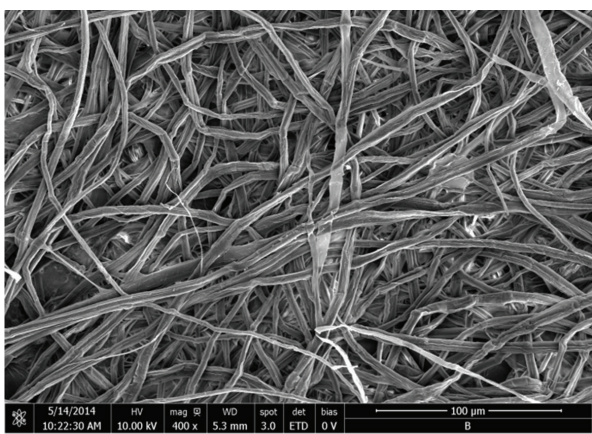

(d)

FIGURE 5: SEM images of pineapple leaf paper: (a), (b) showing surface morphology of the paper prepared at soda concentration $4 \mathrm{wt} \%$ and temperature at $90^{\circ} \mathrm{C}($ kappa number $=29.94)$ and $(\mathrm{c}),(\mathrm{d})$ prepared at soda concentration $5 \mathrm{wt} \%$ and temperature at $130^{\circ} \mathrm{C}(\mathrm{kappa}$ number $=$ 23.07).

$=23.07)$ as shown in Figures 5(c) and 5(d). The connective materials or the residuals of lignin and/or extractives bound cellulose fibers together which were believed to be responsible for the higher mechanical properties.

Tensile strength was selected as a criterion to determine the optimal conditions because it is affected significantly by the pulping variables as shown in Table 3. The data analysis using Minitab 16 suggested that the conditions, soda concentration of $4 \mathrm{wt} \%$, temperature of $105^{\circ} \mathrm{C}$, and pulping time of $20 \mathrm{~min}$, were the optimal conditions. The conditions gave screened yield of $21.29 \mathrm{wt} \%$, tensile index $44.13 \mathrm{kN} \cdot \mathrm{m} / \mathrm{kg}$, burst index $1.76 \mathrm{kPa} \cdot \mathrm{m}^{2}$, and tear index $1.68 \mathrm{~N} \cdot \mathrm{m}^{2} / \mathrm{kg}$. Two pulping experiments (numbers 1 and 2 in Table 6) using the optimum conditions demonstrated that the results agreed with those from the prediction models.

Since the optimal conditions were indicated at the lowest levels of each factor, it was suspicious that the higher screened yield and tensile index might be obtained for soda concentration of lower than $4 \mathrm{wt} \%$. Therefore, two more experiments (numbers 3 and 4 in Table 6) were conducted at soda concentration, pulping temperature, and time of $3 \mathrm{wt} \%$, $110^{\circ} \mathrm{C}$, and $40 \mathrm{~min}$, respectively (the conditions of number 3 in Table 3). Comparison of the results from the experiments at the optimal conditions (numbers 1 and 2 in Table 6) and at the conditions numbers 3 and 4 in Table 6 indicated that screened yield was higher than those of the conditions using soda concentration $4 \mathrm{wt} \%$. However, tensile, burst, and tear indices were lower. Since the desired tensile strength in this research must be at least $40 \mathrm{kN} \cdot \mathrm{m} / \mathrm{kg}$, the conditions using soda concentration of $3 \mathrm{wt} \%$ were, thus, not selected.

\section{Conclusions}

This research studied the effects of independent variables on pulp and paper properties by face-centered composite experimental design. The study aimed to obtain fundamental equations to predict screened yield, kappa number, tensile index, burst index, and tear index. The obtained equations could predict the pulp and paper properties that were close to experimental data. The effects of soda concentration on screened yield and kappa number depended on temperature. At low temperature, an increase of soda concentration increased screened yield but decreased kappa number. However, the opposite effects were found at high temperature. For mechanical properties, the increases of both soda concentration and pulping temperature decreased all the interested mechanical properties. The optimal pulping conditions, to obtain paper with highest tensile index of $44.13 \mathrm{kN} \cdot \mathrm{m} / \mathrm{kg}$, burst index of $1.76 \mathrm{kPa} \cdot \mathrm{m}^{2}$, and tear index of $1.68 \mathrm{~N} \cdot \mathrm{m}^{2} / \mathrm{kg}$, were $4 \mathrm{wt} \%$ soda concentration, $105^{\circ} \mathrm{C}$ pulping temperature, and $20 \mathrm{~min}$ pulping time. The conditions allowed screened yield and kappa number of $21.29 \mathrm{wt} \%$ and 28.12 , respectively.

\section{Competing Interests}

The authors declare that they have no competing interests. 


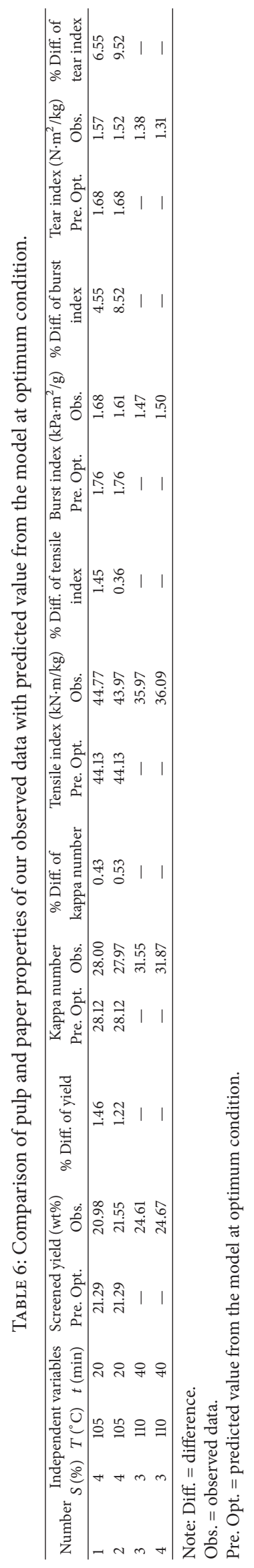




\section{Acknowledgments}

The researchers are grateful for the financial support of this work provided by Suan Dusit University; the apparatus support by the Packaging Technology Department, Chiang Mai University; and the suggestion during paper preparation by Dr. Nakorn Srisukhumbowornchai, King Mongkut's University of Technology Thonburi.

\section{References}

[1] A. Rodríguez, A. Moral, L. Serrano, J. Labidi, and L. Jiménez, "Rice straw pulp obtained by using various methods," Bioresource Technology, vol. 99, no. 8, pp. 2881-2886, 2008.

[2] P. Rezayati-Charani, J. Mohammadi-Rovshandeh, S. J. Hashemi, and S. Kazemi-Najafi, "Influence of dimethyl formamide pulping of bagasse on pulp properties," Bioresource Technology, vol. 97, no. 18, pp. 2435-2442, 2006.

[3] W. D. Wan Rosli, K. N. Law, Z. Zainuddin, and R. Asro, "Effect of pulping variables on the characteristics of oil-palm frond-fiber," Bioresource Technology, vol. 93, no. 3, pp. 233-240, 2004.

[4] N. Cordeiro, M. N. Belgacem, I. C. Torres, and J. C. V. P. Moura, "Chemical composition and pulping of banana pseudo-stems," Industrial Crops and Products, vol. 19, no. 2, pp. 147-154, 2004.

[5] A. V. Tran, "Chemical analysis and pulping study of pineapple crown leaves," Industrial Crops and Products, vol. 24, no. 1, pp. 66-74, 2006.

[6] P. Khristova, S. Gabir, S. Bentcheva, and S. Dafalla, "Sodaanthraquinone pulping of sunflower stalks," Industrial Crops and Products, vol. 9, no. 1, pp. 9-17, 1998.

[7] Production of Pineapple, March 2015, http://faostat3.fao.org/ browse/Q/QC/E.

[8] Z. Daud, M. Z. M. Hatta, A. S. M. Kassim, and A. M. Aripin, "Analysis of the chemical compositions and fiber morphology of pineapple (Ananas comosus) leaves in Malaysia," Journal of Applied Sciences, vol. 14, no. 12, pp. 1355-1358, 2014.

[9] D. Fengel and G. Wegener, Wood, Chemistry, Ultrastructure, Reactions, Walter de Gruyter, New York, NY, USA, 1989.

[10] H. L. Hergert, "Development in organosolv pulping. An overview," in Environmental Friendly Technologies for the Pulp and Paper Industry, R. A. Young and M. Akhtar, Eds., pp. 5-67, John Wiley \& Sons, New York, NY, USA, 1998.

[11] K. Treesuwan, Soda pulping of pineapple leaf [Master's thesis in Chemical Engineering], King Mongkut's Institute of Technology North Bangkok, Bangkok, Thailand, 2005.

[12] L. Jiménez, I. Pérez, M. J. De la Torre, and J. C. García, "The effect of processing variables on the soda pulping of olive tree wood," Bioresource Technology, vol. 69, no. 2, pp. 95-102, 1999.

[13] C. M. Douglas, Design and Analysis of Experiments, John Wiley \& Sons, New York, NY, USA, 2001.

[14] Y. Ziaie-Shirkolaee, J. Mohammadi-Rovshandeh, P. RezayatiCharani, and M. B. Khajeheian, "Influence of dimethyl formamide pulping of wheat straw on cellulose degradation and comparison with Kraft process," Bioresource Technology, vol. 99, no. 9, pp. 3568-3578, 2008.

[15] T. Khampan, N. Thavarungkul, J. Tiansuwan, and S. Kamthai, "Effect of soda pulping variables on pulp and paper properties of pineapple leaves," in International Conference on Science, Technology and Innovation for Sustainable Well-Being, pp. 2324, Khon Kaen, Thailand, July 2009.
[16] W. D. Wanrosli, Z. Zainuddin, and L. K. Lee, "Influence of pulping variables on the properties of Elaeis guineensis soda pulp as evaluated by response surface methodology," Wood Science and Technology, vol. 38, no. 3, pp. 191-205, 2004.

[17] S. I. Mussatto, G. Dragone, G. J. M. Rocha, and I. C. Roberto, "Optimum operating conditions for brewer's spent grain soda pulping," Carbohydrate Polymers, vol. 64, no. 1, pp. 22-28, 2006. 

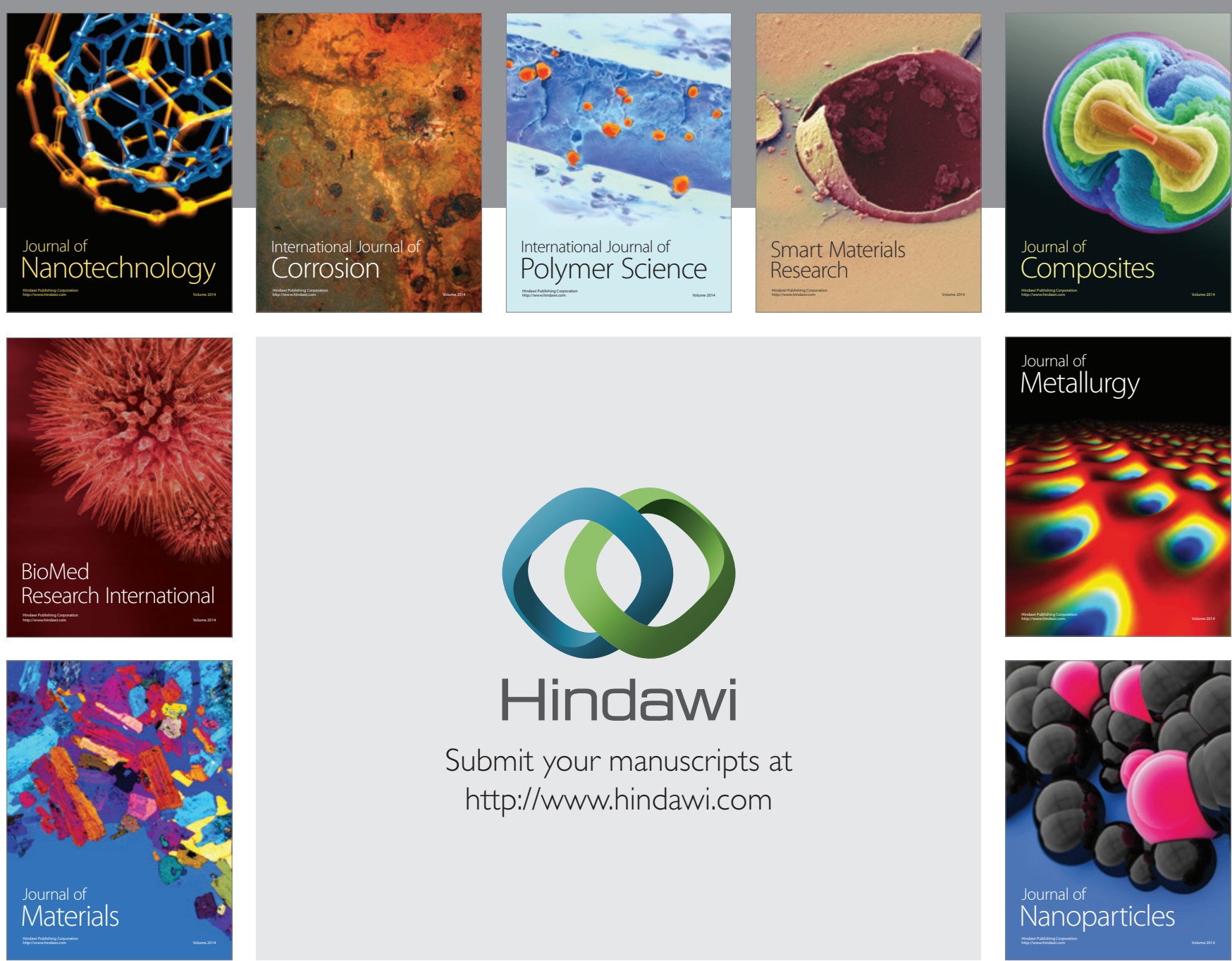

\section{Hindawi}

Submit your manuscripts at

http://www.hindawi.com

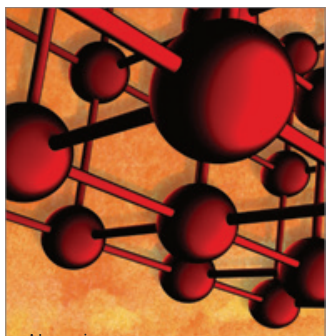

Materials Science and Engineering
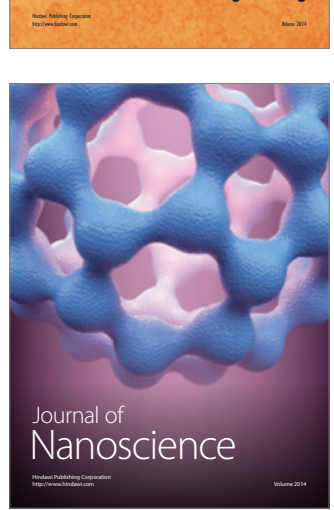
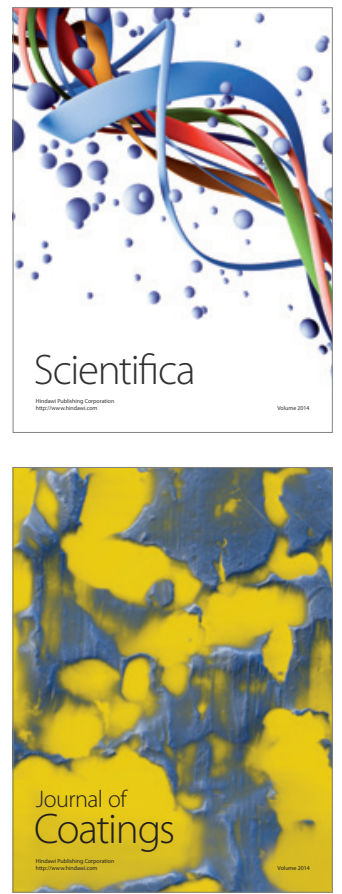
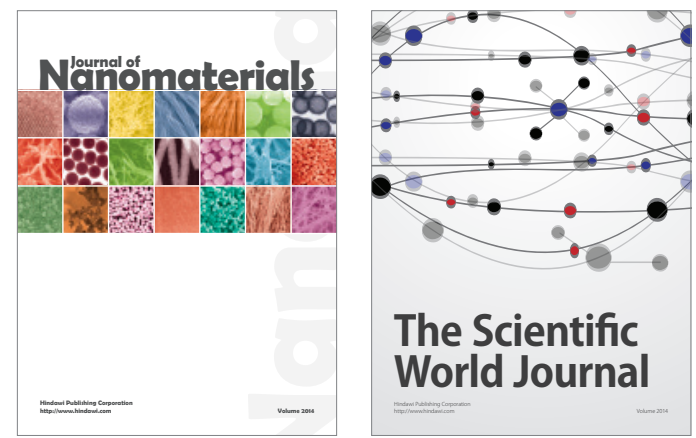

The Scientific World Journal
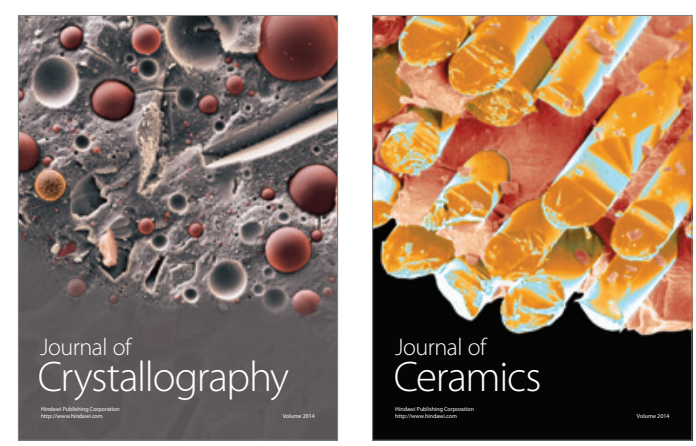
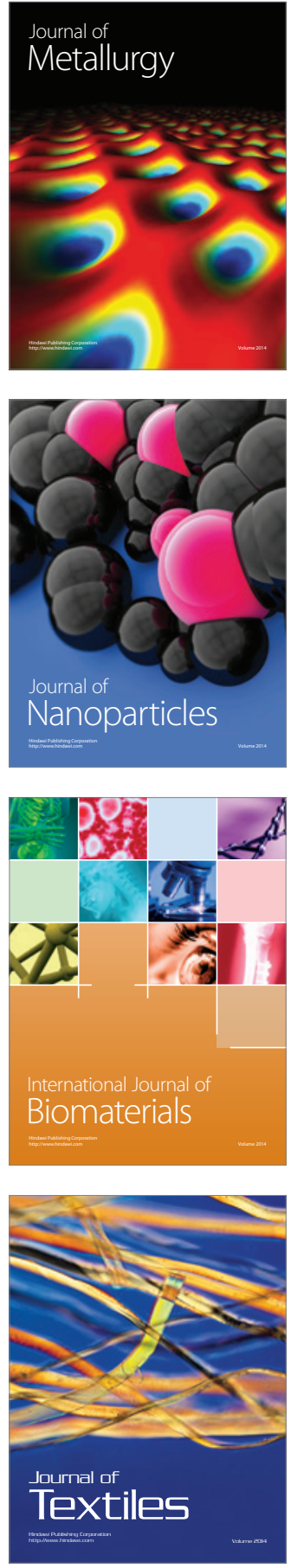